\title{
Efektivitas Antijamur Kombinasi Ketokonazol dengan Minyak Atsiri Sereh Wangi (Cymbopogon nardus (L.) Rendle)
}

\section{The Effectiveness of Antifungal Ketoconazole Combination with Essential Oils of Citronella (Cymbopogon nardus (L.) Rendle)}

\author{
Nilda Lely ${ }^{1}$, Reni Indah Pratiwi ${ }^{2}$, Yunita Listiani Imanda ${ }^{3}$ \\ $1,2,3$ STIFI Bhakti Pertiwi Palembang \\ Email : nildalely@gmail.com
}

\begin{abstract}
ABSTRAK
Minyak atsiri merupakan salah satu senyawa kimia dalam tanaman yang terbukti berpotensi sebagai antijamur. Beberapa penelitian menunjukkan bahwa minyak atsiri sereh wangi (Cymbopogon nardus L. Rendle) mempunyai aktivitas terhadap jamur patogen Tricophyton rubrum, Microsporum canis, dan Epidermophyton floccosum yang dapat menyebabkan penyakit dermatofitosis. Antijamur yang digunakan untuk pengobatan dermatofitosis ini, salah satunya adalah ketokonazol yang merupakan antijamur golongan imidazol. Pada penelitian ini ditentukan efektivitas antijamur kombinasi ketokonazol dengan minyak atsiri sereh wangi terhadap jamur penyebab dermatofitosis. Ekstraksi minyak atsiri menggunakan metode destilasi uap air. Uji efektivitas antijamur kombinasi ketokonazol dengan minyak atsiriri sereh wangi dengan metode difusi agar. Hasil penelitian kombinasi ketokonazol dengan minyak atsiri menunjukkan efek sinergis, karena diameter zona hambat ketokonazol mengalami peningkatan setelah dikombinasikan dengan minyak atsiri. Diameter zona hambat ketokonazol tunggal Tricophyton rubrum ATCC 28188 13,26 mm setelah dikombinasikan menjadi 24,9 mm, Microsporum canis ATCC 32699 12,8 $\mathrm{mm}$ setelah dikombinasikan menjadi 22,56 mm, Epidermophyton floccosum ATCC $5206612,76 \mathrm{~mm}$ setelah dikombinasikan menjadi 19,5 mm. Hal ini disebabkan karena mekanisme kerja yang sinergis dari minyak atsiri sereh wangi (Cymbopogon nardus L. Rendle) dan ketokonazol.
\end{abstract}

Kata kunci: citronella, dermatofitosis, sinergis

\section{ABSTRACT}

Essential oil is one of the chemical compounds in plants that have been proven potential as an antifungal agent. Some studies showed that the essential oil of citronella (Cymbopogon nardus L. Rendle) could resist fungal pathogens Tricophyton rubrum, Microsporum canis and Epidermophyton floccosum, which cause dermatophytosis. Antifungals used for the treatment of dermatophytosis is ketoconazole, which belongs to imidazole group. The purpose of this study was to determine the effectiveness of antifungal ketoconazole in combination with essential oils of citronella against dermatophytosis. Extraction of essential oils was carried out using steam distillation. The effectiveness of antifungal ketoconazole in combination with citronella oil was measured using disk diffusion method. The result of the combination of ketoconazole with essential oils was synergistic as proven by the increased diameter of inhibition zone ketoconazole after combined with essential oils. Ketoconazole inhibition zone diameter single Tricophyton rubrum ATCC $2818813.26 \mathrm{~mm}$ after combined into a $24.9 \mathrm{~mm}$, Microsporum canis ATCC $3269912.8 \mathrm{~mm}$ after combined into a $22.56 \mathrm{~mm}$, Epidermophyton floccosum ATCC $5206612.76 \mathrm{~mm}$ after combined into 19, $5 \mathrm{~mm}$. This is because the synergitic mechanism of action of essential oils of citronella (Cymbopogon nardus L. Rendle) and ketoconazole.

Key words: citronella, dermatophytosis, synergistic 


\section{PENDAHULUAN}

Dermatofitosis adalah infeksi jamur yang menyerang jaringan yang mengandung zat tanduk (keratin) yang terdapat pada kuku, rambut, dan stratum korneum pada epidermis, yang disebabkan oleh jamur dermatofita (Sutanto, 1998). Jamur yang menyebabkan dermatifitosis adalah genus Tricophyton, Epidermophyton dan Microsporum. Infeksi jamur sering berkaitan dengan gangguan daya tahan tubuh, apabila daya tahan tubuh menurun, maka pengobatan jamur sering mengalami kegagalan. Demikian juga pengobatan infeksi dermatofitosis tidak berhasil jika pemakaian obat tidak sesuai dengan aturan. Penggunaan antijamur yang tidak sesuai dengan aturannya sering menjadi penyebab terjadinya resistensi jamur. Selain itu, resistensi juga dapat disebabkan karena kesalahan dalam mendiagnosis, dosis obat tidak tepat, frekuensi pemakaian kurang, rute penggunaan salah dan ketidakpatuhan pasien terhadap terapi (Elin dkk, 2008).

Salah satu obat anti jamur yang banyak digunakan dalam pengobatan dermatofitosis adalah golongan azole. Azole merupakan senyawa sintetis yang dapat digolongkan menjadi imidazol atau triazole. Ketokonazol merupakan azole oral pertama yang digunakan secara klinis (Goodman \& Gilman, 2008).

Selain pengobatan sintetik, pengobatan infeksi jamur juga banyak yang memanfaatkan potensi tanaman. Salah satu tanaman yang memiliki aktifitas tinggi terhadap jamur dan berkhasiat sebagai antijamur adalah sereh wangi (Cymbopogon nardus L. Rendle.) yang termasuk dalam familia Graminae. Komponen utama sereh wangi adalah sitronela dan geraniol. Kedua senyawa tersebut mempunyai sifat antibakteri dan antijamur (Nasrun dan Nuryani, 2007). Menurut Yulvianti (2014) minyak atsiri sereh wangi mengandung komponen sitronelal 32-45\%, geraniol 12-18\% dan sitronelol $11-15 \%$. Terbukti pada penelitian yang dilakukan oleh Sulastri (2014) menyebutkan bahwa minyak atsiri sereh wangi pada konsentrasi $1 \%$ dapat menghambat jamur Tricophyton rubrum (13,3 mm), Tricophyton mentagrophytes $(11,2 \mathrm{~mm})$, dan Candida albicans (19,4 mm).

Senyawa-senyawa antijamur yang diberikan secara bersamaan dapat memberikan efek yang sinergis, hasil yang dinyatakan sinergis apabila terjadi pertemuan atau peningkatan dari dua zona hambat (Goodman \& Gilman, 2008). Untuk meningkatkan efektifitas pengobatan infeksi jamur dan mengurangi resistensi serta efek samping sudah dilakukan beberapa penelitian dengan mengkombinasi antara obat sintetis dengan obat tradisional. Seperti penelitian yang dilakukan oleh Shaaban dkk (2013) melaporkan kombinasi minyak atsiri M. Piperita dengan gentamisin menunjukkan efek sinergis terhadap bakteri Micrococcus luteus, Streptococcus pneumonia, dan memiliki efek additif terhadap bakteri Escherichia coli, Staphylococcus aureus, Salmonella typhimurium, dan Bacillus cereus.
Berdasarkan latar belakang tersebut, maka dilakukan penelitian tentang kombinasi ketokonazol dengan minyak atsiri sereh wangi (Cymbopogon nardus L. Rendle) terhadap jamur dermatofitosis. Dari hasil penelitian ini diharapkan efek antijamur kombinasi ketokonazol dengan minyak atsiri sereh wangi memberikan efek yang sinergis.

\section{METODE}

\section{Bahan dan sampel penelitian}

Bahan yang digunakan dalam penelitian ini antara lain daun dan batang sereh wangi (Cymbopogon nardus (L) Rendle), nutrien agar, ketokonazol (Dexa), etanol, aquadest, $\mathrm{NaCl}$ fisiologis, jamur Tricophyton rubrum, Epidermophyton floccosum, Microsporum canis.

\section{Prosedur Kerja \\ Sampel}

Sampel yang digunakan dalam penelitian ini adalah daun dan batang sereh wangi (Cybopogon nardus L. Rendle) yang diambil di Jl. Sofyan Kenawas Kelurahan Gandus Kecamatan Gandus Palembang.

\section{Isolasi Minyak Atsiri}

Isolasi minyak atsiri sereh wangi dengan metode destilasi uap air. $5 \mathrm{~kg}$ daun dan batang sereh wangi dirajang halus, kemudian didestilasi uap air. Minyak atsiri yang didapat dipisahkan dengan corong pisah, tambahkan natrium sulfat anhidrat untuk menarik air yang kemungkinan masih terdapat dalam minyak atsiri (Djamal, 2012).

\section{Identifikasi Minyak Atsiri}

Pemeriksaan Organoleptis, meliputi pemeriksaan warna, bau dan rasa.

a. Pemeriksaan warna

Dilakukan dengan melihat langsung minyak atsiri hasil destilasi secara visual.

b. Pemeriksaan bau

Dilakukan dengan mencium bau minyak atsiri yang menguap diatas kertas saring.

c. Pemeriksaan rasa

Dilakukan dengan meneteskan minyak atsiri pada ujung lidah kemudian dibuang.

\section{Pemeriksaan Tetapan Fisika}

a. Kelarutan Minyak atsiri sereh wangi.

Kocok 1 bagian volume minyak atsiri sereh wangi dengan 4 bagian volume etanol $96 \% \mathrm{P}$, terjadi larutan jernih. Biarkan selama 24 jam pada suhu antara $20^{\circ}$ hingga $30^{\circ}$, tidak tampak butir-butir pada permukaan larutan (Depkes, 1995).

b. Penentuan Bobot Jenis (BJ)

Minyak atsiri yang didapat dihitung menggunakan piknometer

Piknometer volume $10 \mathrm{ml}$ ditimbang pada neraca analitik. Piknometer diisi minyak atsiri sereh wangi, ditutup lalu ditimbang. Nilai massa didapat dengan mengurangkan berat masing-masing piknometer 
berisi minyak atsiri dengan berat piknometer kosong (Depkes, 1995).

\section{Pembuatan Larutan Uji}

\section{a. Larutan minyak atsiri sereh wangi}

Larutan uji minyak atsiri sereh wangi dibuat dengan konsentrasi $10 \%, 5 \%, 1 \%$ dan $0,5 \%$ yang dilarutkan kedalam etanol destilat.

b. Pembuatan Larutan Kombinasi

Konsentrasi minyak atsiri sereh wangi 1\% 5\% 10\% dikombinasikan dengan larutan ketokonazol 0,01\% konsentrasi yang memiliki daya hambat resisten pada jamur penyebab dermatofitosis.

\section{Pembuatan Medium Pembenihan Jamur}

39 gram serbuk PDA dilarutkan dalam $1 \mathrm{~L}$ air suling dipanaskan sampai mendidih dan diaduk homogen, sterilkan dalam autoklaf pada suhu 121 oC selama 15 menit (Dwidjoseputro, 1998).

\section{Peremajaan Jamur}

Jamur uji diinokulasi dengan jarum ose ke media agar miring, kemudian diinkubasi pada suhu $20-25{ }^{\circ} \mathrm{C}$ selama 3-5 hari hingga diperoleh pertumbuhan yang normal (Brooks dkk, 2005).

\section{Pembuatan Suspensi Jamur Uji}

Koloni jamur lalu disuspensikan ke dalam $\mathrm{NaCl}$ fisiologis sebanyak $5 \mathrm{ml}$ dalam kuvet dan kocok homogen. Kekeruhan suspensi mikroba uji diukur dengan alat spektrofotometer UV-Vis dengan panjang gelombang $530 \mathrm{~nm}$ dengan transmitan $90 \%$ (Depkes, 1995).

\section{Uji Penghambatan Pertumbuhan Jamur}

Teteskan suspensi jamur sebanyak 0,1 ml ke dalam $10 \mathrm{ml}$ media agar, lalu homogenkan, kemudian tuangkan di atas cawan petri yang berisi $10 \mathrm{ml}$ media agar yang telah memadat dan diratakan. Dibiarkan pada suhu kamar selama 15 menit. Setiap jamur uji ditempatkan pada 3 cawan petri untuk tiap larutan uji dan pengujian dilakukan sebanyak tiga kali (triplo). Cakram steril dicelupkan ke dalam masing - masing konsentrasi zat uji yang telah disiapkan kemudian diletakkan pada permukaan media agar yang telah diinokulasi dengan jamur. Cawan petri PDA diinkubasi pada suhu $20-25^{\circ} \mathrm{C}$ selama 3-5 hari. Kemudian diukur diameter zona bening (clear zone) yang terbentuk dengan menggunakan jangka sorong (Brooks dkk, 2005).

\section{Analisa Data}

Daya hambat yang diperoleh dibuat tabulasi perbandingan aktivitas terhadap jamur uji yang digunakan pada berbagai perbandingan kombinasi ketokonazol dengan zat uji dianalisa secara deskriptif

\section{HASIL DAN PEMBAHASAN}

1. Hasil destilasi uap air dari $5 \mathrm{~kg}$ sereh wangi (Cymbopogon nardus L. Rendle) diperoleh minyak atsiri sebanyak $12 \mathrm{ml}$ dengan rendemen sebesar $0,24 \%(\mathrm{v} / \mathrm{b})$

2. Hasil uji pendahuluan terhadap minyak atsiri dari Sereh Wangi (Cymbopogon nardus L. Rendle) sebagai berikut:

\section{a. Hasil Pemeriksaan Organoleptis}

Tabel 1. Pemeriksaan organoleptis minyak atsiri dari sereh wangi (Cymbopogon nardus L. Rendle)

\begin{tabular}{|c|c|l|}
\hline No & Pengamatan & \multicolumn{1}{|c|}{ Hasil } \\
\hline 1. & Warna & Kuning jernih \\
\hline 2. & Rasa & Pedas \\
\hline 3. & Bau & Khas tanaman sereh wangi \\
\hline
\end{tabular}

b. Hasil Pemeriksaan Tetapan Fisika

Tabel 2. Kelarutan dan bobot jenis minyak atsiri sereh wangi (Cymbopogon nardus L. Rendle)

\begin{tabular}{|c|l|l|}
\hline No & \multicolumn{1}{|c|}{ Kriteria } & Hasil Pengujian \\
\hline 1. & $\begin{array}{l}\text { Kelarutan dalam etanol } \\
\text { pa }\end{array}$ & Larut $(1: 2)$ \\
\hline 2. & Bobot Jenis & $0,8832 \mathrm{~g} / \mathrm{ml}$ \\
\hline
\end{tabular}

Minyak atsiri sereh wangi berwarna kuning jernih, rasa sedikit pahit serta mempunyai bau yang khas seperti sereh wangi. Bobot jenis minyak atsiri sereh wangi sebesar $0,8832 \mathrm{~g} / \mathrm{ml}$. Menurut standar EOA (Essential Oil Association) yang menganalisis minyak atsiri sereh wangi diperoleh bobot jenis minyak atsirisereh wangi 0,886-0,894 Jadi bobot jenis minyak atsiri sereh wangi yang diteliti mendekati standar EOA (Guenther, 2006).

3. Diameter hambat minyak atsiri dari Sereh Wangi (Cymbopogon nardus L. Rendle) pada konsentrasi 0,5\%, $1 \%, 5 \%$ dan $10 \%$ ( $/ \mathrm{v}$ ) dapat dilihat pada tabel berikut: 
Tabel 3. Rata-Rata Diameter Hambat Minyak Atsiri dari Sereh Wangi (Cymbopogon nardus L. Rendle) pada jamur dermatofitosis Tricophyton rubrum, Microsporum canis, Epidermophyton floocosum.

\begin{tabular}{|c|c|c|}
\hline Bakteri Uji & $\mathrm{K}(\%)$ & $\begin{array}{c}\text { Diameter } \\
\text { hambat rata- } \\
\text { rata }(\mathrm{mm}) \pm \\
\text { SD }\end{array}$ \\
\hline $\begin{array}{c}\text { Tricophyton } \\
\text { rubrum } \\
\text { ATCC 28188 }\end{array}$ & $\mathrm{K}(+)$ & $13,26 \pm 0,28$ \\
\cline { 2 - 3 } & $\mathrm{K}(-)$ & $0 \pm 0$ \\
\cline { 2 - 3 } & $10 \%$ & $24,9 \pm 0,65$ \\
\cline { 2 - 3 } & $5 \%$ & $16,23 \pm 0,23$ \\
\cline { 2 - 3 } & $1 \%$ & $13,63 \pm 0,28$ \\
\cline { 2 - 3 } canis & $0.5 \%$ & $8,96 \pm 0,40$ \\
\hline ATCC 32699 & $\mathrm{K}(+)$ & $12,8 \pm 0,4$ \\
\cline { 2 - 3 } & $\mathrm{K}(-)$ & $0 \pm 0$ \\
\cline { 2 - 3 } & $10 \%$ & $22,56 \pm 0,25$ \\
\cline { 2 - 3 } & $5 \%$ & $14,4 \pm 0,3$ \\
\cline { 2 - 3 } & $1 \%$ & $10,56 \pm 0,55$ \\
\cline { 2 - 3 } & $0.5 \%$ & $7,13 \pm 0,05$ \\
\hline \multirow{4}{*}{$\begin{array}{c}\text { Epidermophyton } \\
\text { floccosum ATCC }\end{array}$} & $\mathrm{K}(+)$ & $12,76 \pm 0,35$ \\
\cline { 2 - 3 } 52066 & $\mathrm{K}(-)$ & $0 \pm 0$ \\
\cline { 2 - 3 } & $10 \%$ & $19,5 \pm 0,2$ \\
\cline { 2 - 3 } & $5 \%$ & $11,5 \pm 0,36$ \\
\cline { 2 - 3 } & $1 \%$ & $9,5 \pm 0,69$ \\
\cline { 2 - 3 } & $0.5 \%$ & $6,13 \pm 0,81$ \\
\hline
\end{tabular}

Jamur yang digunakan dalam penelitian ini adalah beberapa jamur penyebab penyakit dermatofitosis yaitu Tricophyton rubrum ATCC 28188, Microsporum canis ATCC 32699, dan Epidermophyton floccosum ATCC 52066 yang diperoleh dari Laboratorium Mikrobiologi Fakultas Kedokteran Universitas Indonesia.

Aktifitas antifungi minyak atsiri sereh wangi terhadap jamur Tricophyton rubrum ATCC 28188, Microporum canis ATCC 32699, dan Epidermophyton floccosum ATCC 52066 pada konsentrasi $10 \%, 5 \%, 1 \%$ dan $0,5 \%$ menunjukkan adanya hambatan pertumbuhan jamur. Hasil pengukuran diameter hambat pada jamur Tricophyton rubrum ATCC 28188 berturut-turut sebesar 24,9 mm, 16,23 mm, 13,63 mm dan $8,96 \mathrm{~mm}$. Pada jamur Microsporum canis ATCC 32699 diameter hambat berturut-turut sebesar 22,56 $\mathrm{mm}, 14,4 \mathrm{~mm}, 10,56 \mathrm{~mm}$ dan 7,13 mm. Dan pada jamur Epidermophyton floccosum ATCC 52066 diameter hambat berturut-turut sebesar 19,5 mm, 11,5 mm, 9,5 $\mathrm{mm}$ dan $6,13 \mathrm{~mm}$. Hasil ini menunjukkan tingginya aktivitas antijamur minyak atsiri dari sereh wangi (Cymbopogon nardus (L.) Rendle) terhadap ketiga jamur uji Aktivitas antijamur tersebut diduga berasal dari senyawa-senyawa golongan terpenoid.

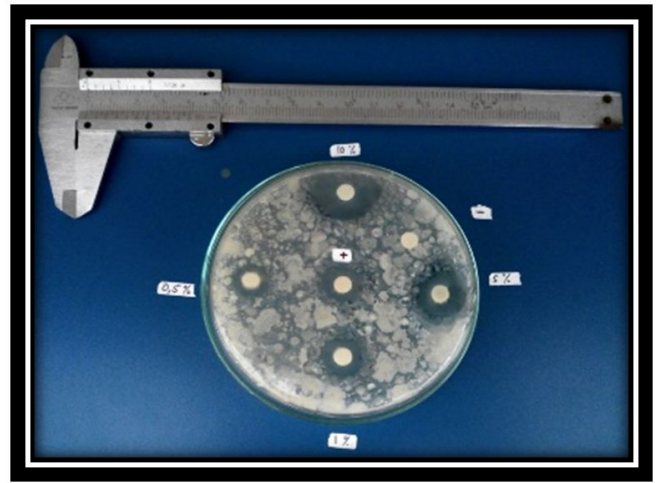

Gambar 1. Gambar Diameter Hambat Minyak Atsiri Sereh Wangi 10\%, 5\%, 1\% Tunggal Dan Ketokonazol 0,01\% Tunggal Terhadap Jamur Dermatofitosis Tricophyton rubrum ATCC 28188

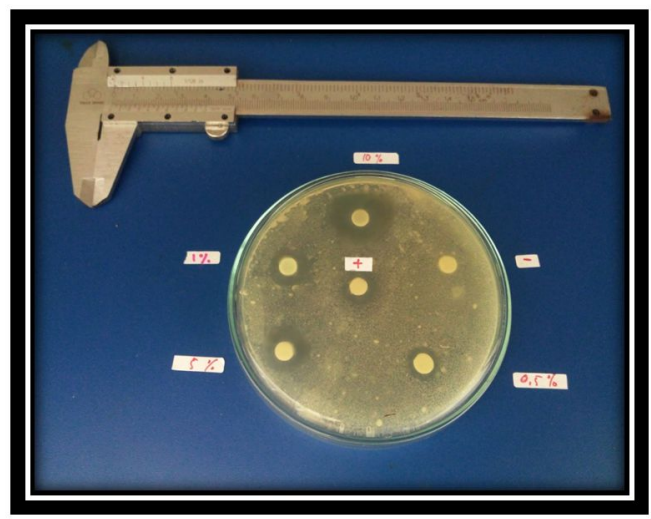

Gambar 2. Gambar Diameter Hambat Minyak Atsiri Sereh Wangi 10\%, 5\%, 1\% Tunggal Dan Ketokonazol 0,01\% Tunggal Terhadap Jamur Dermatofitosis Microsporum canis ATCC 32699

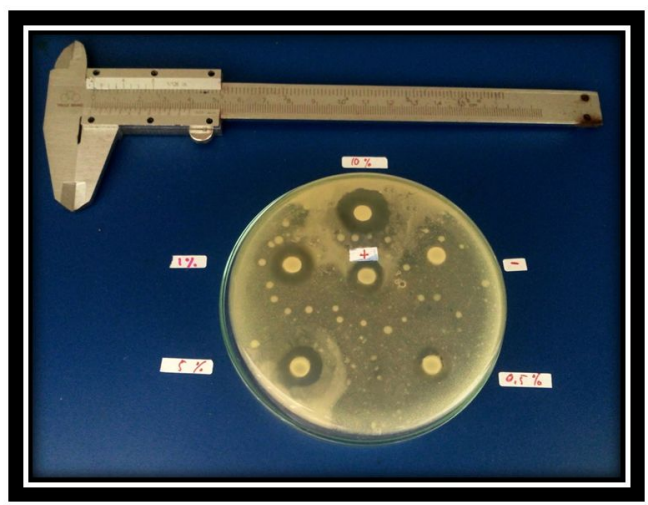

Gambar 3. Gambar Diameter Hambat Minyak Atsiri Sereh Wangi 10\%, 5\%, 1\% Tunggal Dan Ketokonazol 0,01\% Tunggal Terhadap Jamur Dermatofitosis Epidermophyton floccosum ATCC 52066

4. Diameter hambat kombinasi dari ketokonazol pada konsentrasi 0,01\% dengan minyak atsiri Sereh Wangi (Cymbopogon nardus L. Rendle) pada konsentrasi $1 \%, 5 \%$ dan $10 \%(\mathrm{v} / \mathrm{v})$ dapat dilihat pada tabel berikut: 
Tabel 4. Rata-Rata Diameter Hambat kombinasi ketokonazol dengan Minyak Atsiri dari Sereh Wangi (Cymbopogon nardus L. Rendle) pada jamur dermatofitosis

\begin{tabular}{|c|c|c|}
\hline Bakteri uji & $\begin{array}{l}\text { Zat uji } \\
\mathrm{K}(\%)\end{array}$ & $\begin{array}{c}\text { Diameter hambat } \\
\text { Rata-rata }(\mathrm{mm}) \pm \mathrm{SD}\end{array}$ \\
\hline \multirow{5}{*}{$\begin{array}{l}\text { Tricophyton } \\
\text { rubrum } \\
\text { ATCC } 28188\end{array}$} & $\mathrm{~K}(+)$ & $13,1 \pm 0,17$ \\
\hline & $\mathrm{K}(-)$ & $0 \pm 0$ \\
\hline & $\mathrm{K}+10 \%$ & $26,33 \pm 0,15$ \\
\hline & $\mathrm{K}+5 \%$ & $20,53 \pm 0,05$ \\
\hline & $\mathrm{K}+1 \%$ & $14,36 \pm 0,15$ \\
\hline \multirow{5}{*}{$\begin{array}{l}\text { Microsporum } \\
\text { canis } \\
\text { ATCC } 32699\end{array}$} & $K(+)$ & $12,85 \pm 0,07$ \\
\hline & $\mathrm{K}(-)$ & $0 \pm 0$ \\
\hline & $\mathrm{K}+10 \%$ & $25,36 \pm 0,05$ \\
\hline & $\mathrm{K}+5 \%$ & $18,16 \pm 0,11$ \\
\hline & $\mathrm{K}+1 \%$ & $13,56 \pm 0,11$ \\
\hline \multirow{5}{*}{$\begin{array}{l}\text { Epidermophyton } \\
\text { floccosum ATCC } \\
52066\end{array}$} & $K(+)$ & $12,46 \pm 0,05$ \\
\hline & $K(-)$ & $0 \pm 0$ \\
\hline & $\mathrm{K}+10 \%$ & $23,96 \pm 0,11$ \\
\hline & $\mathrm{K}+5 \%$ & $16,6 \pm 0,1$ \\
\hline & $\mathrm{K}+1 \%$ & $12,83 \pm 0,25$ \\
\hline
\end{tabular}

Aktivitas antijamur kombinasi ketokonazol 0,01\% dengan minyak atsiri sereh wangi konsentrasi $1 \%, 5 \%$ dan $10 \%$ pada semua jamur uji menunjukkan adanya peningkatan diameter hambat. Diameter hambat ratarata ketokonazol $0,01 \%$ pada jamur Tricophyton rubrum ATCC 28188 sebesar 13,1 mm yang termasuk kategori resisten secara invitro. Setelah ditambahkan minyak atsiri sereh wangi $1 \%, 5 \%$, dan $10 \%$ menjadi $14,36 \mathrm{~mm}, 20,53 \mathrm{~mm}$, dan 26,33 mm. Dari data tersebut terlihat adanya efek sinergis. Pada jamur Microsporum canis ATCC 32699 ketokonazol tunggal 0,01\% memberikan diameter hambat sebesar $12,85 \mathrm{~mm}$. Setelah kombinasikan dengan minyak atsiri sereh wangi $1 \%$, $5 \%$, dan $10 \%$ menjadi $13,56 \mathrm{~mm}, 18,16 \mathrm{~mm}, 25,36$ $\mathrm{mm}$. Dari data tersebut terlihat adanya efek sinergis. Pada jamur Epidermophyton floccosum ATCC 52066 ketokonazol tunggal $0,01 \%$ memberikan diameter hambat sebesar $12,46 \mathrm{~mm}$. Setelah dikombinasikan dengan minyak atsiri sereh wangi $1 \%, 5 \%$, dan $10 \%$ menjadi $12,83 \mathrm{~mm}, 16,6 \mathrm{~mm}$, dan 23,96 mm. Dari data tersebut terlihat adanya efek sinergis dari kombinasi ketokonazol dengan minyak atsiri sereh wangi.

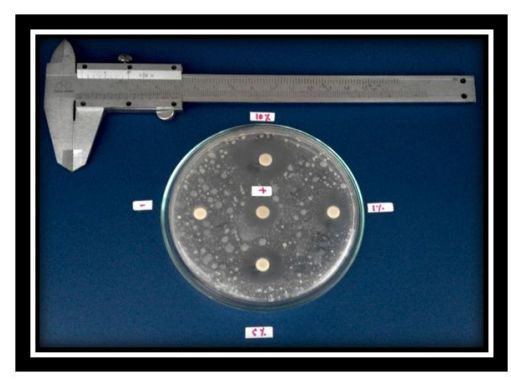

Gambar 4. Diameter Hambat Kombinasi Ketokonazol 0,01\% Dengan Minyak Atsiri Sereh Wangi 10\%, 5\% Dan 1\% Terhadap Jamur Dermatofitosis

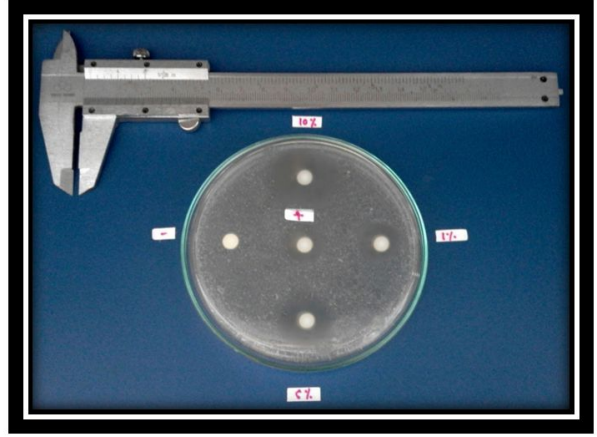

Gambar 5. Diameter Hambat Kombinasi Ketokonazol 0,01\% Dengan Minyak Atsiri Sereh Wangi 10\%, 5\% Dan 1\% Terhadap Jamur Dermatofitosis

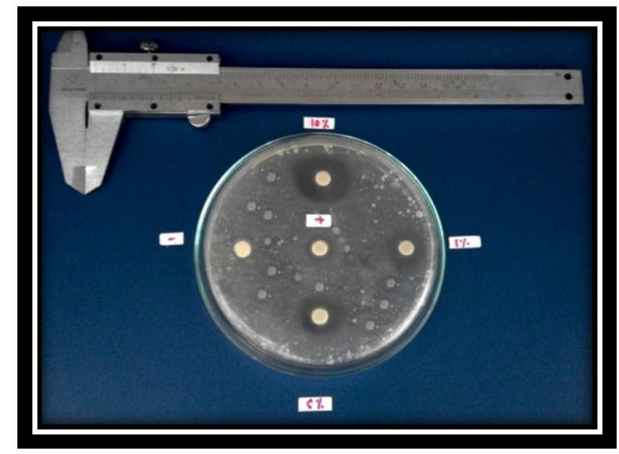

Gambar 6. Diameter Hambat Kombinasi Ketokonazol 0,01\% Dengan Minyak Atsiri Sereh Wangi 10\%, 5\% Dan 1\% Terhadap Jamur Dermatofitosis

Meningkatnya diameter hambat kombinasi ketokonazol dengan minyak atsiri sereh wangi (Cymbopogon nardus L. Rendle) disebabkan karena adanya senyawa pada minyak atsiri sereh wangi yang memiliki efek antifungi yang sinergis dengan ketokonazol. Efek antijamur senyawa golongan azo adalah berinteraksi dengan C-14 $\alpha$ demetilase (enzim P450 sitokrom) untuk menghambat demetilase lanosterol menjadi ergosterol yang merupakan sterol penting untuk membran jamur. Proses penghambatan ini akan mengganggu fungsi jamur dan meningkatkan permeabilitas membran sel jamur (Mustamim, 2015).

\section{SIMPULAN}

Kombinasi ketokonazol dengan minyak atsiri sereh wangi (Cymbopogon nardus (L) Rendle) memiliki efek sinergis secara invitro dalam menghambat pertumbuhan jamur dermatofitosis Tricophyton rubrum ATCC 28188, Microsporum canis ATCC 32699, dan Epidermophyton floccosum ATCC 52066.

\section{PUSTAKA}

Brooks, Geo.F., Janet, S.B., Stephen, A.M. 2005. Jawetz, Melnick, \& Adelberg's Medical microbiology. Jakarta: Penerbit EGC.

Dachriyanus. (2004). Analisis struktur senyawa organic secara spektroskopi. Padang: Universitas Andalas 
Depkes RI. (1995). Farmakope Indonesia (Edisi IV). Jakarta: Departemen Kesehatan RI.

Djamal, R. (2012). Kimia bahan alam: Prinsip-prinsip dasar isolasi dan identifikasi. Padang: Universitas Baiturahman. Hal 193,199,200,221.

Dwidjoseputro, D. (1998). Dasar-dasar mikrobiologi. Jakarta: Universitas Indonesia. Hal: 20, 40.

Elin, Yulinah, S., Retnosari, Andjarwati., I Sigit., Ketut, I Adnyana., Prayitno, A. S., dan Kusnandar. (2008). Iso Farmakoterapi. Jakarta: ISFI

Feriyanto Y. E, Sipahutar, P. T, dkk. (2013). Pengambilan minyak atsiri daun dan batang serai wangi menggunakan metode destilasi uap dan air dengan pemanasan microwave. Journal Teknik POMITS, 2, I, 93 - 94

Gandjar, Indarawati., Sjamsyuriza. W., dan Oetari, Aryanti dkk. (2006). Mikologi dasar dan terapan. Jakarta: Yayasan Obor Indonesia

Ganjewela, D. (2009). Cymbopogon essential oil: chemical chomp osition and bioactivities. Inetrnational journal of essential oil therapeutics, 56-65.

Goodman \& Gilman, (2008), Manual of pharmacolog and teraupetics. USA: The Mc. Grau - Hill Companies.

Guenther, E. (1990). Minyak atsiri. (Jilid III). Jakarta: Universitas Indonesia

Guenther, E. (2006). Minyak atsiri. (Jilid I), diterjemahkan oleh S. Ketaren. Jakarta:

Universitas Indonesia.

Irianto, Koes. (2015). Memahami Berbagai Penyakit : Penyebab, Gejala, Penularan, Pengobatan, Pemulihan, dan Pencegahan. Bandung : CV. Alfabeta.

Ketaren. (1985). Pengantar teknologi minyak atsiri. jakarta: Balai Pustaka.

Knobloch, K.A., B. Paul., H Ilber, Weigand, and W. Weil. 1989. Antibacterial and Antifungal properties of essential oil components. J. Ess. Oil. 1: 119-128.

Maya, Paulina. 2008. https://mikrobiafiles. wordpress.com /2008/05/paulina-maya078114126.pdf. Diakses pada tanggal 12 Januari 2016.

Mustamim, Yusdar. 2013. Bioaktivitas minyak atsiri sereh (Cymbopogon citratus stapf.)

dalam menghambat pertumbuhan jamur mallassezia furfur Penyebab panu (Ptiarisis versicolor). Makasar: Universitas Hasanudin.

Nasrun dan Y. Nuryani, (2007). Penyakit layu bakteri pada nilam dan strategi pengendaliannya. Jurnal Litbang Per-tanian 26 (I). www.pustakadeptan.go.id/publikasi/p3261072.pdf. diakses tanggal 25 Maret 2008.
Prasetyo, U. (2013). Aktivitas antibakteri kombinasi ekstrak etanol daun jambu monyet (Anacardium occidentale L.) dan ampisilin terhadap escherichia coli sensitif dan multiresisten antibiotik. Naskah Publikasi. Surakarta: Universitas Muhammadiyah Surakarta.

Pratiwi, T. S., 2008. Mikrobiologi farmasi. Yogyakarta, Erlangga.

Sastrohamidjojo. (2002). Kimia minyak atsiri. FMIPA Universita Gadjah Mada. Jogjakarta.

Setiawati, W. Murtiningsih, R. Hasyim. (2011). Laboratory and field evaluation of esential oil from cymbopogon nardus as oviposition deterrent and ovicidal activities againts helocoverpa armigera hubner on chili pepper. Indonesia journal of agricultur science 12(1). Indonesia. 9 - 16.

Shaaban, H. A., Ahmed, M. B.M., El-sideek., and May, M. Amer. (2013). Study on the antimicrobial activity and synergistic/ antagonistic effect of interactions between antibiotics and some spice essential oils againts pathogenic and Food-spoiler micro- organisms, Journal of Applied Sciences Research, 9 (8), 5076-5085.

Sujudi, (2002). Mikrobiologi kedokteran. Jakarta : Universitas Indonesia.

Sulastri, H. (2014). Uji aktivitas minyak atsiri daun dan batang serai wangi (Cymbopogon nardus L. Rendle) terhadap jamur Tricophyton rubrum, Tricophyton mentagrophytes, dan Candida albicans. Skripsi. Palembang: Sekolah Tinggi Ilmu Farmasi.

Sutanto, I., Suhariah., K, Pudji., dan Sungkar, S. (1998). Buku ajar parasitologi kedokteran. Jakarta: Fakultas Kedokteran.

Wei, Lee Seong \& Wendy Wee. (2012). Chemical composition and antimicrobial activity of cymbopogon nardus citronella oil againts system bacteria of aquatic animal. Iranian Journal of Microbiologi. Malaysia. vol 5 no. 2/ Juni 2013. HIm 147-152.

Imani, Z. A. (2014). Uji aktivitas antijamur ekstrak etanol daun mangga bacang (Mangifera foetida L.) terhadap candida albicans secara in vitro. Pontianak : Univ. Tanjung Pura

Wijayakusuma, H. (2001). Tumbuhan berkhasiat obat indonesia: rempah, rimpang. Dan umbi. Jakarta: Milenia Populer.

Yulvianti, M., dkk. (2014). Pengaruh perbandingan pelarut N-heksana-etanol terhadap kandungan sitronelal hasil ekstraksi serai wangi (Cymbopogon nardus). Jurnal Integrasi Proses vol 5 no 1, 8-14. 